\title{
QUE UNIDADE, FRAGMENTAÇÃO E O DIREITO INTERNACIONAL
}

\author{
Raphael Carvalho de Vasconcelos ${ }^{1}$
}

\section{RESUMO}

A moderna concepção unitarista do direito internacional encontra-se atualmente desafiada por teorias fragmentárias que estruturam a ordem jurídica global em esferas temáticas aparentemente autônomas. Resta à teoria do direito estabelecer se tal fragmentação conformaria questão jurídica consolidada ou mera situação fática compatível com alguma proposta de unidade. Este trabalho pretende estruturar as linhas gerais do debate entre a unidade e a fragmentação do direito internacional a partir do positivismo moderno, isto é, das teorias de Hans Kelsen e de H.L.A. Hart, para, com base nos escritos de Martti Koskenniemi e Klaus Günther, desenvolver uma contribuição à sistematização do direito das gentes nesse contexto por muitos identificado como pós-moderno e, especificamente no direito, como pós-positivista.

Palavras-chave: Direito internacional; unidade; fragmentação.

\section{UNITY, FRAGMENTATION AND INTERNATIONAL LAW}

\begin{abstract}
The modern unitarist conception of international law is challenged nowadays by fragmentarian theories which structure the global legal order into apparently self-contained thematic spheres. It is an attribution of the law theory to establish whether the aforementioned fragmentation constitutes a consolidated juridical matter or a merely fact situation which fits any unitarist proposal. This article intends to organize the general lines of the discussion between the unity and the fragmentation of international law starting from the modern positivism, it means from Hans Kelsen's and H.L.A. Hart`s theories, to, based on studies by Martti Koskenniemi and Klaus Günther, develop a contribution to the international law theory in this context commonly labeled as post-modern or, specifically in the law doctrine, as postpositivist.
\end{abstract}

Keywords: International law; unity; fragmentation.

\footnotetext{
${ }^{1}$ Mestre em Direito Internacional pela Universidade de São Paulo, Mestre em Direito Internacional pela Universidade do Estado do Rio de Janeiro, Doutorando em Direito Internacional pela Universidade do Estado do Rio de Janeiro, professor da Universidade Federal Rural do Rio de Janeiro, Advogado. Contato: raphaelvasconcelos@ig.com.br
} 


\section{Introdução}

O estudo do direito internacional sempre apresentou desafios e segue atualmente constituindo fonte de intensos e controvertidos debates. As discussões de outrora giravam principalmente em torno da aplicação ao direito das gentes do modelo científico, sistêmico, por meio do qual o positivismo buscava estruturar uma teoria unitarista e, portanto, em conformidade com a modernidade. Nesse contexto, a coerência do ordenamento global se via desafiada pela relação entre os diversos ordenamentos jurídicos internos dos Estados com a normativa incipiente que buscava regular as relações internacionais.

Essa estruturação lógica do direito internacional assistiu, entretanto, a uma série de transformações políticas e sociais que acabaram estabelecendo novos paradigmas teóricos ao seu estudo. Se, por um lado, sua condição de direito acabou consolidada, os desafios à unidade foram potencializados pela pluralidade de fontes, órgãos legiferantes, jurisdições e, fundamentalmente, pelo surgimento de novos sujeitos de direitos e deveres internacionais. A lógica da unidade passou a ser substituída por teorias fragmentárias, as quais se baseiam na estruturação do direito internacional em uma série de esferas temáticas que, principalmente no âmbito das organizações internacionais, normatizam a ordem global em sistemas aparentemente autônomos.

De certo, o sistema unitarista que posiciona o Estado-nacional no centro da produção legislativa internacional não se sustenta nessa nova realidade. Resta à teoria do direito, todavia, estabelecer se a fragmentação conformaria questão jurídica consolidada ou mera situação fática compatível com alguma proposta unitarista, ainda que diversa daquelas do positivismo tradicional.

Este trabalho pretende sistematizar as linhas gerais do debate entre a unidade e a fragmentação do direito internacional a partir do positivismo moderno, é dizer, do estudo da relação entre os ordenamentos internos e o internacional, e entender as reviravoltas ocorridas em seu âmbito até o panorama atual de aparente fragmentação em sistemas temáticos autônomos. Na primeira parte, os estudos de Hans Kelsen e H.L.A. Hart servem de fundamentação teórica à apresentação de um breve panorama da perspectiva positivista tradicional do direito internacional. A atual conformação aparentemente fragmentada da ordem 
legal global é, sob a ótica das teorias de Martti Koskenniemi, objeto da seção seguinte. Na terceira e última parte deste trabalho propõe-se a aplicação de propostas substantivas ao direito internacional, tais como as apresentadas por Klaus Günther, como instrumentos capazes de possibilitar que se conclua finalmente pelo reconhecimento de características unitárias no contexto fragmentado vislumbrado por muitos no atual direito das gentes.

\section{Unidade do direito internacional: modernidade e positivismo}

Sendo a superação da modernidade parte importante da pauta atual das ciências sociais, aconselhável se faz hoje iniciar qualquer estudo do direito a partir da sistematização teóricocientífica característica da experiência moderna. O que se afirma, na verdade, é que a superação a que se refere exige a prévia compreensão da concepção eminentemente moderna, ou seja, tecnicista, mecânica, codificada, é dizer, positivista do direito ${ }^{2}$.

A estruturação lógica das normas em critérios de validade constitui o traço mais marcante do positivismo jurídico. No âmbito específico do direito internacional, a busca por uma fórmula, uma técnica hábil a explicar e, principalmente, fundamentar a natureza de seus institutos acabou por exigir sua inclusão nas construções teóricas que surgiam para racionalizar o direito à luz da modernidade ${ }^{3}$.

A racionalização do mundo repercutiu juridicamente, portanto, em tentativas de construção de teorias objetivas para o direito e capazes, consequientemente, de sistematizá-lo como ciência. Para tanto, tais teorizações baseavam-se fundamentalmente na estrita separação entre direito e moral e na consolidação de um critério de validade hábil à justificação da obrigatoriedade das leis.

\footnotetext{
${ }^{2}$ Ainda que forte resistência teórica exista à associação da modernidade ao positivismo e da pós-modernidade ao pós-positivismo, é de se perceber que a doutrina internacionalista tende a sugerir tais associações. Nesse sentido, DOLINGER, Jacob. Dignidade: o mais antigo valor da humanidade. os mitos em torno da declaração universal dos direitos do homem e da constituição brasileira de 1988. as ilusões do pós-modernismo/pós-positivismo. a visão judaica. Revista do Direito Constitucional e Internacional. Ano 18 - v. 70 - jan.-mar/2010. pp. $24-90$ e CASELLA, Paulo Borba. Fundamentos do direito internacional pós-moderno. Tese de Titularidade apresentada à FADUSP: São Paulo, 2006.

${ }^{3}$ Exemplos importantes da estruturação positivista apontada se verificam, por exemplo, nas teorias de Hans Kelsen, autor austríaco que buscou em sua obra Reine Rechtslehre - Teoria Pura do Direito -, de 1934, sistematizar o positivismo jurídico de civil Law e de H.L.A. Hart, autor inglês que condensou suas propostas em seu livro The Concept of Law - O Conceito de Direito -, de 1961.
} 
O afastamento da moralidade se reflete claramente, por exemplo, na distinção proposta por Hans Kelsen em $1934^{4}$ entre o que seria o "ser" - sein - e o "dever-ser" - sollen. Em sua Teoria Pura do Direito o autor positivista identifica o "dever-ser" como motriz ideal da norma jurídica e sustenta, nesse sentido, que o naturalmente posto seria apenas declarado e não produziria, necessariamente, efeitos, enquanto a norma estabelecida, válida, teria eficácia plena e sustentar-se-ia, principalmente, na possibilidade de sanção ${ }^{5}$.

Também o jurista inglês H.L.A. Hart apresentou em sua obra The Concept of Law ${ }^{6}$, de 1961, uma proposta de teoria do direito eminentemente positivista e, portanto, fundada em preceitos modernos. Sua formação jurídica em um ordenamento de common law, estruturado a partir dos precedentes e na construção do direito pelo costume, na prática dos tribunais, denuncia-se no posicionamento da atividade judicial no centro de sua racionalização do mundo jurídico e apresenta, portanto, perspectiva teórica diversa daquela de Kelsen, ainda que, de maneira geral, ambas as teorias mostrem-se bastante convergentes em uma série de aspectos ${ }^{7}$.

$\mathrm{Na}$ teoria jurídica hartiana, a chamada regra de reconhecimento se apresenta como critério supremo de validade e acaba denotando o cunho claramente positivista de sua sistematização do direito ao representar o estabelecimento de um parâmetro absolutamente independente da moral para justificar a validade do direito. A regra de reconhecimento seria, dessa maneira, uma questão de fato consubstanciada na aceitação de um critério de validade ${ }^{8}$. Hart, diferentemente de Kelsen, trabalhou a noção de perspectiva interna do sujeito enxergando, a partir disso, a obrigatoriedade da norma independentemente da ameaça de sanção ${ }^{9}$. Os sujeitos submetidos a uma determinada ordem jurídica não agiriam, assim, em conformidade com as

\footnotetext{
${ }^{4}$ KELSEN, Hans. Teoria pura do direito. São Paulo: Martins Fontes, 2003.

${ }^{5}$ Ibid. p. 217 - 218. No que se refere especificamente à validade, Kelsen propôs uma concepção escalonada da ordem jurídica estruturada em critérios hierárquicos. Dessa sistemática decorre a conclusão de que, por um lado, uma norma seria hierarquicamente superior a outra quando justificasse e legitimasse sua criação e, por outro, que uma norma seria válida quando criada em conformidade com a norma hierarquicamente superior.

${ }^{6}$ HART, H.L.A. The concept of law. Oxford: Clarendon Press, 1961.

${ }^{7}$ Ambas as propostas positivistas à teorização do direito buscam fundamentação em critérios de validade de normas e defendem rígidos critérios de separação entre o direito e a moralidade.

${ }^{8}$ Ibid. p. 107.

${ }^{9}$ Hart dedica o capítulo quarto inteiro de sua obra Ibid. pp. 49-76. a críticas às teorias do direito que se constroem com base na idéia da sanção.
} 
regras estabelecidas pelo receio da sanção como sustentado por Kelsen, mas simplesmente por reconhecerem a normatividade da regra ${ }^{10}$.

Ao abordar o direito internacional, Hart parte novamente da perspectiva interna do participante e procura racionalizar a obrigatoriedade normativa em meio à inexistência de um sistema organizado de sanções. Tal sistematização do direito das gentes sugere o reconhecimento de um conjunto de regras primárias obrigatórias para os sujeitos, apesar de, todavia, não identificar regras secundárias que regulem a aplicação dessas regras primárias. Nesse sentido, por não conseguir encontrar uma regra de reconhecimento que estabelecesse critérios de validade para a normativa do direito internacional, o autor inglês não o via como um sistema jurídico, mas apenas como um simples conjunto de preceitos legais ainda não organizado de maneira sistemática e coerente ${ }^{11}$.

Dentre as conclusões que podem ser extraídas da negação do caráter sistêmico do direito internacional cumpre destacar o comprometimento de qualquer concepção unitarista de seu corpo normativo. A unidade poderia ser encarada, de fato, como uma das mais perceptíveis conclusões decorrentes do reconhecimento do conjunto de normas internacionais como direito e, portanto, como um sistema jurídico organizado.

O protagonismo da sanção na teoria de Kelsen, conforme anteriormente apontado, ou seja, da possibilidade de coerção decorrente do descumprimento da norma válida, constitui sua mais marcante diferença em relação à construção teórica hartiana. $\mathrm{O}$ direito, segundo sua teoria pura, consubstanciaria, assim, uma ordem normativa que regularia as ações individuais mediante a prescrição de condutas sob a ameaça de sanção. Não seria demais afirmar, nesse sentido, que a obrigatoriedade derivada do receio de uma sanção encontrar-se-ia no cerne do sistema proposto pelo autor austríaco.

A partir de tal perspectiva, mesmo reconhecendo seu estado primitivo, Kelsen outorga ao direito internacional o status de direito propriamente dito e não o reconhece, portanto, como um mero conjunto de normas. O direito internacional consubstanciaria, assim, um sistema

\footnotetext{
${ }^{10}$ Ibid. pp. 99-100.

${ }^{11}$ Ibid. pp. 230-231.
} 
normativo que regularia as ações dos $\operatorname{Estados}^{12}$, prescrevendo condutas e estabelecendo sanções - guerra e represálias - para seu descumprimento ${ }^{13}$.

Também a questão hierárquica se coloca à prova na abordagem do direito internacional à luz das teorias de Kelsen. Ainda que hoje organizações multilaterais como a Organização das Nações Unidas possuam importante papel no estabelecimento de regras comuns ao convívio dos sujeitos de direito internacional, tanto à época da concepção proposta pela teoria pura quanto agora, não seria possível identificar um órgão central dotado de atribuições legislativas emanadas por um texto legal fundamental vinculante, tal qual e de maneira tão coercitiva quanto à constituição e as instituições que garantem o fiel cumprimento de seus preceitos no ordenamento interno dos Estados ${ }^{14}$.

Kelsen busca resolver tais entraves dividindo as normas de direito internacional entre aquelas criadas por meio de atos de Estado, ou seja, consolidado positivamente em tratados internacionais, e aquelas decorrentes do costume internacional, o direito internacional geral. Entre as normas de costume internacional, a pacta sunt servanda possuiria especial importância, pois serviria de base ao direito internacional emanado das declarações de vontade e estabeleceria entre as duas espécies descritas uma relação hierárquica ${ }^{15}$.

Ainda que a sistematização teórica do autor austríaco favoreça a aproximação do direito internacional aos critérios estabelecidos pela racionalidade jurídica positivista à caracterização de um sistema jurídico, não se deve encarar a teoria de Hart como absolutamente avessa ao caráter vinculante do direito internacional, posto que mesmo "as regras de uma estrutura simples são, assim como a regra básica dos mais avançados sistemas, vinculantes se elas forem aceitas e assim funcionarem"16.

Especificamente no que se refere à unidade, o autor inglês propõe o abandono do debate acerca do caráter sistêmico do direito internacional e concentra-se no reconhecimento de seus preceitos como vinculantes. Hart observa, ainda, que suas características rudimentares não

\footnotetext{
${ }^{12}$ Ainda que em determinado momento a teoria pura do direito vislumbre a possibilidade de existirem outros sujeitos titulares de direitos e deveres no plano internacional, KELSEN, Op. cit., nota 03. pp. 355 e 358.

${ }^{13}$ Ibid. pp. 356-357.

${ }^{14}$ Ibid. pp. 358-359.

15 Ibid. p. 360.

${ }^{16}$ HART, Op. cit., nota 05. p. 230. "In verbis": "The rules of the simple structure are, like the basic rule of the more advanced systems, binding if they are accepted and function as such."
} 
constituiriam necessariamente seu formato definitivo e vislumbra, finalmente e de maneira essencialmente projetiva, o estado de transição, no qual o direito internacional se encontraria rumo à formação de um sistema jurídico organizado e, portanto, unitário ${ }^{17}$.

Kelsen, por sua vez, ao reconhecer a existência de sanções no plano internacional acaba aproximando o direito internacional ao direito interno dos Estados e, igualmente de maneira projetiva, acaba vislumbrando o surgimento de uma "comunidade universal de direito mundial"18 centralizada. Tal elemento universalista não é, entretanto, meramente programático, tendo em vista que a teoria pura estrutura, de forma bastante clara, a existência de "uma unidade cognoscitiva de todo o Direito, o que significa que podemos conceber o conjunto formado pelo Direito internacional e as ordens jurídicas nacionais como um sistema unitário de normas justamente como estamos acostumados a considerar como uma unidade a ordem jurídica do Estado singular." 19

Essa concepção monista do direito, que inclui em um único corpo normativo os direitos interno dos Estados e o internacional, enfrenta oposições doutrinárias que formulam sistematizações apartadas em planos normativos distintos, o que, para a teoria pura, consistiria fundamentalmente na concepção de ordens jurídicas apoiadas em distintas normas fundamentais. Tais construções teóricas iriam, ainda segundo o doutrinador austríaco, de encontro ao caráter científico da, por ele denominada, ciência jurídica, a qual teria como tarefa a descrição de seu objeto como algo uno ${ }^{20}$.

O fator decisivo a ser considerado no embate entre a concepção unitária e dualista - ou pluralista $^{21}$ - da relação existente entre o direito interno e o direito internacional estaria na questão da possibilidade de existência de contradições normativas entre o local e o geral. Dessa forma, caso se pudesse conceber a validade simultânea de normas contraditórias, uma no plano estadual e outra no internacional, a unidade não se sustentaria ${ }^{22}$.

Importante salientar ainda, nesse momento, que a relação observada entre o local e o global acaba por refletir questionamentos análogos feitos a respeito da moral que, ao ser

\footnotetext{
${ }^{17}$ Ibid. pp. 230-231.

${ }^{18}$ KELSEN, Op. cit., nota 03. p. 364.

${ }^{19}$ Ibid. p. 364.

${ }^{20}$ Ibid. pp. 364-365.

${ }^{21}$ Ibid. p. 364.

22 Ibid. p. 365.
} 
definitivamente apartada do sistema de validade proposto, acabou sendo desconsiderada na teoria pura como ordem normativa válida. Assim, para Kelsen, caso concebidos de forma dual ou plural -, o direito internacional e o direito interno não poderiam coexistir simultaneamente como válidos e esse constituiria o cerne da insustentabilidade das teorias dualistas ${ }^{23}$.

As divergências que surgem a partir da contraposição dos dois possíveis desenhos da teoria monista referem-se exclusivamente à hierarquia normativa e repercutem, principalmente, na determinação do fundamento de validade do direito internacional. O conteúdo e funções da ordem normativa una e coerente seriam, entretanto, os mesmos tanto no caso de identificação da norma fundamental no plano interno quanto no costume internacional ${ }^{24}$.

O elemento mais marcante da forma como o direito internacional se apresenta nas teorias positivistas denota, mais uma vez, sua imersão na experiência moderna. O direito, e destacadamente o direito das gentes, surge e se estrutura de maneira absolutamente vinculada à idéia do Estado-nação e a questão unitarista se refere basicamente à compatibilização do plano jurídico internacional às distintas ordens legais nacionais. As dúvidas e críticas quanto à unidade do direito internacional não eram, como se verifica atualmente na doutrina internacionalista e será demonstrado adiante, propriamente relacionadas à perspectiva interna do direito internacional, mas, entretanto, moderna e positivamente fundadas em sua relação com o direito interno dos Estados.

\section{0 direito internacional contemporâneo: entre unidade e fragmentação}

O incômodo causado pela falta de respostas às mazelas humanas e pela dificuldade de se colocar aquilo que é logicamente racionalizado em prática está exatamente no cerne do debate pós-moderno, ainda que o próprio conteúdo desse termo, criado à luz das angústias modernas ${ }^{25}$, seja colocado em xeque, contestado e considerado, por muitos, impróprio e superficial ${ }^{26}$.

\footnotetext{
${ }^{23}$ Ibid. pp. 365-366.

${ }^{24}$ Ibid. p. 378.

${ }^{25}$ BITTAR, Eduardo Carlos Bianca. O direito na pós-modernidade. Rio de Janeiro: Forense Universitária, 2005. p. 27. defende a autonomia da pós-modernidade relacionando-a diretamente com o pensamento moderno.

26 BAUMAN, Zygmunt. Modernidade líquida. Rio de Janeiro: Jorge Zahar Ed., 2001, passim, por exemplo, constrói sua argumentação referindo-se à modernidade atual como líquida, a qual se contrapõe à rigidez do que ele chama de estágio sólido original.
} 
No direito, especificamente e conforme já ressaltado, a modernidade repercutiu em sua sistematização teórica, na construção do pensamento jurídico tecnicista, mecânico, codificado, é dizer, positivista ${ }^{27}$, ao qual o prefixo indicativo da busca por uma superação hábil a trazer respostas concretas a suas faltas e lacunas aderiu. Pós-positivismo se tornou, nessa toada, a vertente jurídica da pós-modernidade, mas a tentativa de se criar algo inovador acabou em certa medida apenas potencializando aquilo que já se encontrava no arcabouço do pensamento moderno; a valorização e a proteção do ser humano ${ }^{28}$.

A imagem do patinador de Emerson ${ }^{29}$ que, ao enfrentar a tênue camada de gelo de um lago congelado, encontra na rapidez de seus movimentos a técnica necessária para deslizar de forma segura e seguir em frente serve ainda inequivocamente à descrição dessa existência cada vez mais, com a licença do lugar-comum, globalizada, veloz e uniformizante. A dificuldade de superação de paradigmas faz com que, nesse cenário, o prefixo "pós" aparente tão somente servir à reafirmação da modernidade, mas, no encalço da consolidação de uma série de alterações de perspectivas, embora não se admita ainda a definitiva superação do moderno, vive-se hoje, ao menos, o desafio de tal superação ${ }^{30}$.

O mundo se torna dia após dia menor, as relações humanas são hoje transnacionais, multiconectadas, produto direto da técnica, das máquinas, do apreço à razão e à tecnologia ${ }^{31}$. $\mathrm{O}$ direito $^{32}$ e a sociologia ${ }^{33}$ se ocupam cada vez mais da relação entre o local e o global, entre o

${ }^{27}$ CASELLA, Paulo Borba.Op. Cit. Nota 01. pp. 56 - 57.

${ }^{28}$ Ibid. p. 66.

${ }^{29}$ EMERSON, Ralph Waldo. Essays and lectures. New York: The Library of América, 1982. p. 364, em seu ensaio Prudence de 1841, in verbis: "In skating over thin ice, our safety is in our speed".

${ }^{30}$ CASALMIGLIA, Albert. Postpositivismo. Doxa 21:209-220, 1998. p. 209.

${ }^{31}$ KENNEDY, David. The international human rights movement: part of the problem? In: Harvard Human Rights Journal. Vol. 15, 2002. p. 116.

${ }^{32}$ Por exemplo, CANÇADO TRINDADE, Antônio Augusto. Tratado de direito internacional dos direitos humanos - vol. I. Porto Alegre: Sergio Antonio Fabris Editor, 1997.; . A proteção internacional dos direitos humanos e o Brasil (1948-1997): as primeiras cinco décadas. Brasília: UnB, 1998.; PIOVESAN, Flávia. Direitos humanos e o direito constitucional internacional. São Paulo: Editora Max Limonad Ltda., 1996.; Direitos humanos globais, justiça internacional e o brasil. In: AMARAL JUNIOR, Alberto do, org; Perrone-Moisés, Cláudia, org. O Cinquentenário da Declaração Universal dos Direitos do Homem. São Paulo: EDUSP, 1999.; Direitos humanos: desafios da ordem internacional contemporânea. In: PIOVESAN, Flávia, coord. Direitos Humanos. Curitiba: Juruá, 2007.; GÜNTHER, Klaus. Rechtspluralismus und universaler code der legalität: globalisierung als rechtstheoretisches problem. In: WINGERT, Lutz; GÜNTHER, Klaus. Die öffentlichkeit der vernunft und die vernunft der öffentlichkeit. Frankfurt: Suhrkamp, 2001.; KENNEDY, Op. cit., nota 30.; CAGGIANO, Monica Herman S. Os direitos fundamentais e sua universalização. In: Revista Brasileira do Direito Constitucional, n. 4, jul./dez., 2004.; KOSKENNIEMI, Martti. Global legal pluralism: multiple 
geral e o específico, o universal e o relativo, o uniforme e o multicultural. Alguns se posicionam firmemente em defesa da sobreposição do geral ao local, outros defendem a diversidade acusando defeitos na uniformização, mas tanto em um quanto no outro grupo existem aqueles que claramente tentam refinar o discurso e harmonizar aquilo que aparentemente surge como antagônico e inconciliável ${ }^{34}$.

As relações entre os sujeitos de direito internacional passaram, nesse contexto, gradualmente da coexistência westfaliana à cooperação. Em meio a tal evolução, o clássico conceito de soberania relativizou-se e toda a técnica jurídica do direito das gentes passou a exigir novas sistematizações ${ }^{35}$. Inserido nessa redefinição do paradigma soberano ${ }^{36}$, o debate acerca da relação entre o geral e o específico repercutiu em toda a estruturação teórica do direito internacional e traduz-se hoje, principalmente, nas discussões acerca de seu caráter unitário ou fragmentado à luz, principalmente, da análise da relação dos Estados com os novos sujeitos multilaterais de direito internacional.

A mera possibilidade de se cogitar a conformação fragmentada do direito internacional constitui aspecto dessa pós-modernidade jurídica que busca o distanciamento da visão tecnicista, sistêmica e, portanto, unitarista de outrora ${ }^{37}$. Importante ressaltar que a perceptível diluição do conceito clássico de soberania não se apresenta apenas à instrumentalização da institucionalização da atuação integrada de duas ou mais unidades políticas independentes no plano internacional, mas decorre, na verdade e de forma bem mais ampla, do afastamento da perspectiva moderna de centralidade do Estado nas relações internacionais ${ }^{38}$.

O caráter assistemático do direito na atualidade surgiria, assim e de maneira absolutamente contraditória, em decorrência de fatores eminentemente modernos comumente

regimes and multiple modes of thought. Harvard, 05 de março de 2005 - Palestra. e FISCHER-LESCANO, Andréas; TEUBNER, Gunther. Regime-Kollisionen. Frankfurt am Main: Suhrkamp Verlag, 2006.

${ }^{33}$ Por exemplo, BAUMAN, Op. cit., nota 25 e SANTOS, Boaventura de Souza. Uma concepção multicultural de direitos humanos. In: Lua Nova: Revista de Cultura e Política 39, 1997, pp. 105-124.

${ }^{34}$ CASALMIGLIA, Op. cit., nota 29. p. 210.

${ }^{35}$ LAFER, Celso. A OMC e a regulamentação do comércio internacional: uma visão brasileira. Porto Alegre: Livraria do Advogado, 1998. pp. 19-20.

${ }^{36}$ KOSKENNIEMI, Martti. From apology to utopia: the structure of international legal argument. Nova Iorque: Cambridge University Press, 2005. pp. 242-243.

${ }^{37}$ KOSKENNIEMI, Martti. What is international law for? In: EVANS, Malcolm D. (Edit.). International law. Oxford: Oxford University Press 2006. p 77.

${ }^{38}$ SOARES, Mário Lúcio Quintão. MERCOSUL - Direitos humanos, globalização e soberania. Belo Horizonte: Del Rey, 1999. p. 29. 
englobados no lugar-comum da "globalização ${ }^{39 ",}$, tais como os avanços tecnológicos e a especialização. Tal constatação acaba denunciando de maneira ainda mais forte e cristalina o vínculo existente atualmente no direito entre a superação - o pós - e o que se busca superar - o positivismo. A doutrina internacionalista costuma, nesse contexto atual, entender o pluralismo legal como um problema teórico ameaçador da racionalidade que, de maneira técnica e artificial, buscou construir-se sob uma lógica sistêmica unitarista e, portanto, coerente ${ }^{40}$.

Nessa toada e partindo-se, por exemplo, da análise do direito internacional sob perspectiva constitucionalista e, portanto, eminentemente unitarista, percebe-se com facilidade a fragmentação - ainda que aparente - causada pela tematização autônoma da atividade legislativa no plano global ${ }^{41}$.

Observação cuidadosa do cenário global atual não aponta, esclareça-se, à diluição da importância dos Estados como sujeitos de direito internacional, mas à impossibilidade da atuação isolada e irrestrita. De fato, a nova realidade histórica - global e pós-moderna verificada atualmente nas relações internacionais parece ter intensificado de maneira bastante nítida a interdependência, fenômeno que repercutiu no direito internacional, pós-positivista e pós-nacional, no incremento das chamadas iniciativas de cooperação e integração ${ }^{42}$.

Conflitos podem ocorrer, nesse novo contexto, tanto entre a ordem jurídica nacional e a internacional quanto entre as diversas normativas internacionais hoje existentes e, muitas vezes, ainda que a conformação entre tratados e entre tratados e a lei nacional não configure ou apresente divergências políticas, importantes dúvidas jurídicas podem subsistir e restar insolúveis $^{43}$. A possibilidade de normatização divergente no plano internacional

${ }^{39}$ LEWANDOWSKY, Enrique Ricardo. Globalização e soberania. In: CASELLA, Paulo Borba; CELLI, Umberto. Direito internacional, humanismo e globalidade. São Paulo: Atlas, 2008. pp. 293-294.

${ }^{40}$ HALTERN, Ulrich. Internationales Verfassungsrecht? Anmerkungen zu einer kopernikanischen Wende. In: Archiv des öffentlichen Rechts 128, 2003. p. 516.

${ }^{41}$ Essa pluralidade de lógicas normativas dificulta, na verdade, a própria aplicação do constitucionalismo ao direito das gentes ainda que seu arcabouço teórico não exija necessariamente, por exemplo, exercícios projetivos de criação de uma federação global. Mais em FASSBENDER, Bardo. The meaning of international constitutional law. In: MacDonald/Johnston (Hrsg.). Towards World Constitutionalism. Amsterdam: R.St.J., 2005. p. 839.

${ }^{42}$ PEREIRA, Ana Cristina Paulo. Diferentes aspectos dos sistemas de integração da União Européia e do MERCOSUL: uma abordagem sintética e comparativa. In: PEREIRA, Ana Cristina Paulo. MERCOSUL e união européia: perspectivas da integração regional. Rio de Janeiro: Lúmen Júris, 2006. p. 193.

43 BIELING, Hans-Jürgen. Die Konstitutionalisierung der Weltwirtschaft als Prozess hegemonialer Verstaatlichung, In: BUCKEL, Sonia u.a. (Hrsg.). Hegemonie gepanzert mit Zwang. Baden-Baden: Nomos, 2007. p. 148. 
consubstanciaria, a partir de tais premissas, a chamada fragmentação do direito internacional ${ }^{44}$, ou seja, a especialização técnica das diversas áreas do direito internacional em marcos legais particulares elaborados segundo perspectivas inerentes a sua lógica temática ${ }^{45}$.

Importante se faz ressaltar, nesse momento, a diversidade de conteúdos disponíveis para o termo "fragmentação". Nesse sentido, o direito internacional poderia ser teorizado de maneira compartimentada como um conjunto de sistemas temáticos distintos e autônomos ou, na perspectiva interna de uma dessas lógicas jurídicas específicas - dos direitos humanos, do comércio internacional, do direito do mar -, em relação à sobreposição de normativas internacionais sobre o mesmo tema ${ }^{46}$.

Nesse ponto, pode-se vislumbrar relevante risco surgido a partir da pretensão de fragmentação do direito das gentes. De fato, concebidas as normas internacionais de maneira unitarista, os costumes e tradições nela inseridos tenderiam a traduzir uma perspectiva globalmente compartilhada, ainda que inexistam, certamente, garantias de que projetos políticos hegemônicos particulares não capturariam a estrutura global predominante ${ }^{47}$. De qualquer maneira, a assunção de uma correlação lógico-normativa entre as estruturas aparentemente autônomas poderia, sim e entretanto, dificultar tal usurpação ${ }^{48}$.

De uma forma ou de outra, o pluralismo decorrente, principalmente, da maior institucionalização do direito internacional consubstancia hoje fato e qualquer perspectiva que se adote em sua abordagem deve levar em consideração as alterações ocorridas na organização do espaço global como, por exemplo, o reconhecimento da existência de novos sujeitos de direitos e de obrigações. Nesse sentido, os projetos políticos com pretensões gerais na estruturação fragmentada do direito das gentes não conformariam exclusivamente questões de Estado, submetendo-se à atualmente necessária distinção observável entre os paradigmas do governo e da governança ${ }^{49}$.

\footnotetext{
${ }^{44}$ KOSKENNIEMI, Martti. Global governance and public international Law. In: Kritische Justitz, 37, 2004. p. 243.

${ }^{45}$ KOSKENNIEMI, Martti. The fate of public international law: constitutional utopia or fragmentation? Chorley Lecture: London School of Economics, 2006. p. 30.

${ }^{46}$ DUPUY, Pierre-Marie. L'unité de l'ordre juridique international. In: Recueil des Cours. Academie de Droit International de la Haye, tomo 297, 2002. pp. 428-429.

${ }^{47}$ KOSKENNIEMI, Op. cit., nota 43. p. 243.

${ }^{48}$ SANTOS, Op. cit., nota 32. PP 110 - 111. Constrói sua proposta de hermenêutica diatópica a partir das críticas ao universalismo dos direitos humanos como uma concepção hegemônica, de dominação.

${ }^{49}$ KOSKENNIEMI, Op. cit., nota 43. pp. 241 - 254.
} 
Assim, enquanto a idéia de governo se relacionaria à tradicional concepção política organizacional voltada ao benefício comum, no conceito de governança se encontrariam contidos os interesses individuais que, por diversos fatores, se infiltrariam no sistema político internacional em um jogo de influências que tenderia a favorecer os anseios dos mais fortes ${ }^{50}$.

Dentre os fatores que impediriam a atual viabilidade da aplicação da estruturação teórica tradicional estaria, mais uma vez e fundamentalmente, a impossibilidade de se sustentar o clássico protagonismo dos Estados na estrutura do direito internacional ${ }^{51}$. Caso não se admitisse a referida alteração de perspectiva, complicado se tornaria justificar, por exemplo, o surgimento e desenvolvimento de mecanismos independentes e órgãos específicos para assegurar a eficácia das regras produzidas e a estabilidade das relações estabelecidas atualmente na comunidade internacional ${ }^{52}$.

Importante ressaltar o conteúdo e os limites dessa comunidade que se vê submetida, posto se tratar de um termo que se refere não a uma coletividade humana, mas mormente a uma congregação de entes políticos não-físicos, agentes do direito internacional e freqüentemente mas não necessariamente - dotados de soberania ${ }^{53}$.

Também a própria preferência atual pelo uso do termo "globalização" 54 em detrimento de "internacionalização" no debate jurídico e político internacional denotaria, nesse sentido, séria tendência ao distanciamento da perspectiva tradicional que por tanto tempo vigorou em todos os campos do pensamento humano e que tinha foco central nas clássicas noções de soberania e no reconhecimento do Estado-nação como único sujeito de direito internacional ${ }^{55}$.

De certo, o estado de direito vem desde o século XVIII, ao lado dos princípios liberais do Iluminismo, sendo utilizado pelos juristas como paradigma conceitual aplicável à sociedade

\footnotetext{
${ }^{50}$ Ibid. p. 243.

${ }^{51} \mathrm{O}$ autor não ataca o positivismo clássico de forma direta, mas desenvolve um longo trabalho de relativização do papel do Estado como sujeito central de direitos e deveres no âmbito internacional.

52 Ibid. p. 248. Koskenniemi ressalta que a ONU tem vivenciado tais dificuldades ao depender, por não possuir suas próprias forças armadas, da concessão de soldados por seus membros. Marcante é, nesse exemplo, o império descrito por Koskenniemi tendo em vista o fato de apenas aqueles Estados que já possuem supremacia política internacional têm um contingente militar apropriado para possibilitar essas concessões. Tal estruturação torna, portanto, impossível a aplicação de intervenções militares nesses "Estados-império" e retira da ONU a possibilidade de utilização de mecanismos de coerção contra eles.

${ }^{53}$ AGO, Roberto. Communauté internationale et organisation internationale. In: DUPUY, René-Jean. Manuel sur les organisations internationales. Dordrecht: Martinus Nijhoff Publishers, 1998. p. 3.

${ }^{54}$ LEWANDOWSKY, Op. cit., nota 38. p. 293.

${ }^{55}$ SINGER, Peter. One world. New Haven e Londres: Yale University Press, 2004. p. 08.
} 
internacional, a qual tende a ser percebida de forma análoga ao domínio jurídico interno de um país. Essa analogia tende claramente à estruturação e à justificação do direito internacional como uma ordem jurídica una, dotada de objetividade não constatável nas idéias, preferências e visões políticas e que seria hábil a produzir, portanto, normas gerais, abstratas e pretensamente universais.

A mencionada objetividade normativa - moderna, positivista e genuinamente apartada da política - não seria verificada na prática, entretanto, exatamente por desatender, sob o prisma legislativo, o pressuposto liberal da concretude, segundo o qual o direito deveria se basear em algo palpável, como um comportamento social, para que subjetivismos políticos e constrangimentos ilegais pudessem ser evitados.

De outro lado, no plano hermenêutico, outro pressuposto positivista não verificável de forma empírica na aplicação do direito internacional seria a normatividade, ou seja, a necessidade de aplicação do direito de forma independente de preferências políticas dos agentes envolvidos. Caso a normatividade fosse plenamente vislumbrável na sistemática do direito internacional, a norma se aplicaria, assim, independentemente da vontade dos sujeitos a ela submetidos e essa vinculação cogente não se verifica de maneira plena, todavia no plano jurídico internacional.

A concretude e a normatividade conformariam, portanto, variáveis essenciais às garantias de previsibilidade, segurança jurídica e coercibilidade inerentes à idéia sistêmica do direito e que, de forma concentrada e unitarista, promoveriam sua independência da discricionariedade característica da política. A unidade do direito internacional poderia ser atualmente desarticulada, portanto, exatamente a partir da análise da dinâmica dos dois pressupostos positivistas descritos. Dessa forma, apesar de ser absolutamente possível de forma analógica a identificação da concretude na aproximação da normativa posta às práticas estatais, tais práticas tenderiam hoje ao afastamento da normatividade e ao risco de aproximação da política.

Torna-se possível observar, assim, nessa conformação política cada vez mais influenciada pelo paradigma da governança, instrumentalizado, por exemplo, no fenômeno da fragmentação, que as diversas esferas jurídicas tenderiam a atuar hoje de forma autônoma, 
obedecendo a lógicas e estruturas jurídicas próprias, as quais não respeitariam os referidos pressupostos positivistas da concretude e da normatividade.

Os aspectos plurais diagnosticados em análise fática da atual dinâmica do direito internacional poderiam não indicar necessariamente uma ruptura com o unitarismo sistêmico positivista caso se mostre possível seu enquadramento em algum conceito fechado de direito galgado em concepções teóricas tradicionais. Essa crise unitarista denunciada com freqüência pela teoria jurídica se traduz em diagnósticos fragmentários traçados tanto genericamente para o sistema legal global quanto particularmente na estrutura interna de cada um dos sistemas normativos aparentemente autônomos disponíveis.

A inviabilidade teórica da unidade se vislumbraria entre lógicas, por exemplo, quando da tentativa de se harmonizarem as regras da Convenção do Mar e aquelas da Organização Mundial do Comércio, e, dentro de ordens legais de temáticas específicas tais como a interna do sistema mundial de comércio, quando estudada a relação existente entre a organização estruturada no âmbito do acordo geral e os diversos acordos regionais de comércio existentes.

No caso, por exemplo, do constitucionalismo aplicável ao direito internacional, a hierarquização das normas e dos órgãos jurisdicionais estaria, conforme explicitado anteriormente, no cerne da transposição da perspectiva local àquilo que seria o sistema normativo global ${ }^{56}$. Nesse sentido, o ambiente jurídico internacional se estabeleceria em modelos de criação e consolidação de entes supra-estatais e na uniformização jurisprudencial, ou seja, de forma a se aplicar a estrutura político-jurídica interna dos Estados à esfera internacional.

Na mesma linha conciliatória, o pluralismo legal poderia surgir como alternativa teórica aplicável à análise fática da aparente fragmentação, a qual se caracterizaria na abordagem que busca organizar todas as diferentes ordens jurídicas especializadas que se constroem no plano global compreendendo cada uma delas como autônoma, desvinculada das demais, mas sujeitas a "[...] um sistema de coordenação de regimes, e a um direito inter-sistêmico que substituiria o direito conflitual particular."

\footnotetext{
${ }^{56}$ FASSBENDER, Op. cit., nota 40. p. 838.

${ }^{57}$ KOSKENNIEMI, Op. cit., nota 35. p. 15. No original: " [...] a regime-co-ordination, and inter-system law that would resemble the private law of conflicts."
} 
$\mathrm{Na}$ multiplicidade de estruturas legais que se formam de maneira aparentemente autônoma no direito internacional, a fragmentação propriamente não configuraria, portanto, um desafio estrutural formal tão sério e inconciliável às teorias unitaristas como aquele representado pelo modelo da governança, o qual nessa estrutura repartida acaba se incorporando aos procedimentos normativos e, desafiando a unidade, capturando suas perspectivas fragmentadas.

Há que se ressaltar, entretanto, que mesmo quando admitido o desafio político da governança, a prática do direito internacional tende a demonstrar que em momentos críticos determinados valores universais, os quais consubstanciariam princípios gerais de direito seriam reconhecidos e informariam as lógicas aparentemente autônomas de forma uniformizante. ${ }^{58}$

A assunção da existência de um grupo de princípios universalmente aplicáveis sofre resistência mesmo dentro das correntes de pensamento européias, as quais comumente não apenas admitem a existência de um grupo de valores superiores extraíveis de sua organização sócio-cultural, mas também tendem com freqüência a encará-los como genericamente aplicáveis a toda a humanidade ${ }^{59}$. Em meio a tais críticas, fator que poderia favorecer a concepção de um núcleo conceitual geral seria o papel desempenhado atualmente pela sociedade civil, a qual, mesmo nesse contexto de aparente fragmentação do direito internacional, muitas vezes exige o cumprimento dos acordos e a defesa de determinados valores gerais por seus governos ${ }^{60}$.

Também a questão da hermenêutica do direito internacional, ameaçada pela existência de diversos órgãos de solução de controvérsias e, portanto, hábeis à prolação de entendimentos acerca da interpretação das regras do direito das gentes, acaba denotando, exatamente na institucionalização, surpreendente faceta unitarista na pluralidade. Nesse sentido, sempre que uma organização internacional dotada de arcabouço normativo possui seu próprio órgão de solução de controvérsias observa-se, em tese, um esforço de instrumentalização positivista do

\footnotetext{
${ }^{58}$ Também as teorias do minimalismo e do maximalismo moral de Michel Walzer trabalham a idéia da existência de valores universalmente compartilhados que seriam claramente perceptíveis apenas nos momentos de exceção. WALZER, Michael. Thick and thin, moral argument at home and abroad. Notre Dame: undp, 1994. p. 39.

${ }^{59}$ SANTOS, Op. cit., nota 32. p. 111.

${ }^{60}$ DUPUY, Pierre-Marie. Some reflections on contemporary international law and the appeal to universal values : a response to Martti Koskenniemi. In: European Journal International Law 16, 2005. p. 137. o autor ataca de forma direta o pluralismo fragmentário radical de Koskenniemi, que parece desconsiderar o papel da sociedade civil por exemplo.
} 
direito, o qual pode ser interpretado, na verdade, como um esforço de enquadramento a um padrão geral que integra a atuação desse sujeito internacional à ordem jurídica global ${ }^{61}$.

Fundamental se faz, finalmente, salientar a absoluta alteração de paradigma observável entre a discussão unitarista tradicional e o debate fragmentário atual. Enquanto as teorias positivistas clássicas buscavam estruturar e reconhecer o direito internacional como direito buscando compreender a relação existente entre ordem jurídica geral e os ordenamentos internos dos Estados, a questão interna parece ter sido hoje superada pela multiplicidade de ordens legais que se estabelecem no plano internacional.

A questão do interno com o internacional, fundada no paradigma do Estado-nação, acabou sucumbindo ao reconhecimento de novos atores como sujeitos de direitos e deveres no âmbito do direito das gentes e o debate passou a se concentrar na possibilidade de se estabelecerem regras gerais aos múltiplos sistemas jurídicos especializados que surgiram e nas dificuldades em se aplicarem as teorias positivistas fundadas em critérios hierárquicos de validade a esse novo contexto global $^{62}$.

Importante salientar, finalmente, que a perspectiva fragmentária do direito internacional surge como proposta de análise de dois fenômenos sistêmicos distintos no atual panorama pluralista do direito internacional. Nesse sentido a fragmentação pode se referir, por um lado e em sentido mais abrangente, à independência dos sistemas jurídicos temáticos que de maneira autônoma surgiram e se consolidaram do contexto global, enquanto, por outro lado, pode designar as repartições sistêmicas internas que se apresentam no plano específico de um desses regimes.

\section{Legalidade universal e unidade}

Se, por um lado, a complexa trama normativa do direito internacional na atualidade representa grande avanço quando contraposta às rudimentares concepções teóricas tradicionais que se ocupavam até mesmo da justificação de sua sistematização como ordem jurídica, a

\footnotetext{
${ }^{61}$ DUPUY, Op. cit., nota 45. p. 460.

${ }^{62}$ Ibid. pp. 38-39.
} 
multiplicação de sistemas legais especializados e aparentemente autônomos oferece, por outro, sérios riscos à manutenção de sua coerência orgânica, é dizer, de sua unidade.

Cada esfera particular do interesse humano tende a se estruturar juridicamente, dessa forma, como um sistema legal dotado de axiomas e regras aplicáveis, a princípio, apenas às situações fáticas submetidas a sua respectiva e específica ordem normativa. O estudo do direito internacional atual parece, assim, não homenagear mais o clássico conceito positivista de um único sistema legal logicamente ordenado e hierarquicamente diferenciado. Distintos fenômenos, mormente políticos, converteram o que era uno e indivisível em um aparente pluralismo, ou seja, em uma pluralidade de regimes. ${ }^{63}$

A partir dessas premissas, mister se faz admitir que as alusões à fragmentação do direito das gentes se referem, na maior parte das vezes mas não sempre, à mencionada divisão temática das normas, a qual se verifica atualmente em número expressivo de matérias, mas principalmente, por uma série de fatores circunstanciais, nas questões econômicas, nas conseqüências econômicas relacionadas ao meio ambiente, à migração e ao desenvolvimento, nos direitos humanos e nas questões de segurança $\mathrm{a}^{64}$.

Outro fator importante nessa dinâmica de intensa produção legislativa transnacional especializada reside na participação cada vez menor dos Estados - os clássicos sujeitos de direito internacional - nesses fenômenos legiferantes e no fato de, nessa toada, cada vez mais as normas internacionais se desprenderem dos ordenamentos jurídicos nacionais e aderirem a estruturas formais internacionais compartilhadas, tal qual, por exemplo, aquelas consideradas supranacionais.

A diminuição do papel dos Estados, a multiplicidade de regimes normativos, a intensa e descentralizada produção legislativa transnacional seriam, de certo, fenômenos caracterizadores do pluralismo legal, mas, na perspectiva de Günther, a fragmentação jurídica tornaria discutíveis tanto as soluções jurídicas dadas aos conflitos quanto à própria legitimidade legislativa dos órgãos instituidores das normas ${ }^{65}$.

\footnotetext{
${ }^{63}$ GÜNTHER, Op. cit., nota 31. p. 540 - 541.

${ }^{64}$ Ibid. p. 542.

${ }^{65}$ Ibid. p. 556.
} 
O risco apontado subsistiria, segundo tais teorias, mormente porque a multiplicidade de órgãos legiferantes públicos, privados, nacionais, internacionais, regionais, multilaterais e supranacionais inviabilizariam a aplicação do conceito clássico positivista da unidade do direito como modelo sistêmico fechado, hierárquico e, principalmente, estruturado em um claro esquema de validade de normas nem mesmo dentro de uma das esferas.

Numa tentativa de conformar o pluralismo com a unidade do direito das gentes, surge a proposta, também de Günther, de sua apreciação sob duas perspectivas; a interna e a externa. Assim, sob a perspectiva externa, o pluralismo representaria a fragmentação do direito em uma série de temáticas jurídicas distintas, enquanto, internamente, poder-se-ia reconstruir a perspectiva de um direito uniforme ${ }^{66}$.

De maneira bastante simples, pode-se defender que a constituição de um órgão legiferante internacional deve respeitar as regras estabelecidas em tratados, mas a prática internacional pode muito bem permitir o reconhecimento ou o respaldo de determinados preceitos como obrigatórios e juridicamente vinculantes mesmo que inexistam instrumentos legais que os estabelecessem. Tal discussão urge a retomada da abordagem positivista tradicional do direito internacional, a qual questionava inclusive sua caracterização como direito em vista de sua frágil estrutura, e - ultrapassado tal debate - a natureza jurídica dessas normas.

A aparente desarticulação do conceito clássico de unidade em favor de um pluralismo de regimes estruturados em distintas lógicas jurídicas não se confirmaria em razão do que o autor alemão chama de "código universal da legalidade", um núcleo duro de regras e princípios universalmente aceitos que representariam uma nova perspectiva da unidade do direito global ${ }^{67}$.

De uma maneira ou de outra, a Convenção de Viena sobre o Direito dos Tratados parece ter resolvido tal contenda doutrinária ao admitir em seu artigo 53 expressamente a existência de normas cogentes de direito internacional, as quais se caracterizariam como sendo aceitas e

${ }^{66}$ Ibid. p. 557. "In verbis": "Der Rechtspluralismus stellte für die Rechtstheorie dann insofern eine Herausforderung dar, al ser gleichsam die Schwelle erhöhte, welche die rechtsinterne Begriffsbildung zu überschreiten hätte, um die Einheitsfiktion noch konstruieren zu können.”

${ }^{67}$ A existencia desses princípios vinculantes também é vislumbrada em MELLO, Celso D. de Albuquerque. Direito internacional americano: estudo sobre a contribuição de um direito regional para a integração econômica. Rio de Janeiro: Renovar, 1995. p. 07. 
reconhecidas pela comunidade internacional dos Estados em sua totalidade, sem admitir derrogação, sendo apenas passíveis de modificação por outra com as mesmas características ${ }^{68}$.

\section{Conclusão}

O estudo do direito internacional na atualidade não comporta mais seu enquadramento nos herméticos conceitos tecnicistas das clássicas teorias positivistas modernas. Essa releitura hodiernamente exigida decorre, conforme ressaltado ao longo deste trabalho, principalmente do deslocamento da perspectiva de fundamentação do sistema jurídico global da exclusiva relação entre direito interno e internacional para as divergências na interpretação e na aplicação das normativas que se sobrepõem internacionalmente de maneira concorrente e vinculante.

$\mathrm{Na}$ multiplicidade de estruturas legais que se formam de maneira aparentemente independente no direito internacional, a fragmentação pode muito bem não configurar propriamente, portanto, desafio estrutural formal tão sério e inconciliável às teorias unitaristas como aquele representado pelo modelo da governança, o qual, em uma estrutura repartida, acaba se incorporando mais facilmente aos procedimentos normativos e permitindo a captura de suas perspectivas fragmentadas por um dos sistemas particulares.

A especialização temática apresenta-se como uma das mais importantes características do novo direito das gentes, pautado nesse início de século, principalmente, na participação cada vez maior dos Estados em convenções e acordos que objetivam normatizar de maneira abrangente matérias pontuais e de interesse comum tanto no plano global quanto no regional. Nesse contexto, cada esfera particular do modus vivendi humano tende a se estruturar juridicamente como um sistema legal dotado de axiomas e regras aplicáveis, a princípio, apenas às situações fáticas submetidas a sua respectiva e específica ordem normativa.

Percebe-se, então, que assim como outrora o sistema jurídico geral se apresentava de maneira rudimentar e fundamental se fazia sustentar sua unidade, o direito internacional atual segue desafiado pela ainda incerta dinâmica de interação entre essas diversas esferas legais. $\mathrm{O}$ estudo do direito das gentes parece, na verdade, não homenagear mais o clássico conceito

\footnotetext{
${ }^{68}$ Ibid. p. 07.
} 
positivista de um único sistema legal logicamente ordenado e hierarquicamente diferenciado. Distintos fenômenos, mormente políticos, converteram o que era uno e indivisível em um aparente pluralismo, ou seja, em uma pluralidade de regimes.

Outro fator importante nessa dinâmica de intensa produção legislativa transnacional especializada reside na participação cada vez menor dos Estados - os clássicos sujeitos de direito internacional - em iniciativas legiferantes e no fato de, nessa toada, cada vez mais as normas internacionais se desprenderem dos ordenamentos jurídicos nacionais e aderirem a estruturas formais internacionais compartilhadas, tal qual, por exemplo, aquelas consideradas supranacionais.

Da falta de institucionalização do direito internacional - ao menos quando em comparação com as rígidas estruturas dos Estados soberanos - decorre o debate acerca da existência de regras internacionais apenas nos limites do convencionado em tratados e, diversamente, da possibilidade de se reconhecerem normas principiológicas cogentes ainda que não derivadas de declarações de vontade específicas. A assunção de tal normatividade tácita, da existência desse "código universal da legalidade" como um núcleo duro de regras e princípios universalmente aceitos, redargüiria de maneira bastante consistente, por exemplo, a aparente desarticulação do conceito clássico de unidade em favor de um pluralismo de regimes estruturados em distintas lógicas jurídicas. O universalismo principiológico, é dizer, a aceitação de uma moralidade mínima global, permitiria, assim, a estruturação de uma nova perspectiva da unidade do direito global.

Os princípios basilares do direito internacional seriam, desse modo, inerentes a sua estrutura geral e estariam contidos, sendo necessariamente respeitados, em todos os sistemas normativos específicos. A característica de abrangência desse código de legalidade acaba por afastá-lo de conteúdos substanciais e aproximando-o de elementos formais, os quais naturalmente tenderiam a não pertencer a lógicas jurídicas particulares e a se adaptar, portanto, a todas as ordens temáticas que convivem atualmente no plano internacional.

Em meio à aparente conformação repartida da ordem jurídica internacional, preceitos jurídicos globais ou - em linha com toda a construção teórica aqui desenvolvida - o código universal da legalidade surgiriam, portanto, como instrumentos de preservação da unidade do 
direito internacional na atualidade e a fragmentação constituiria, assim, mera análise superficial de um contexto fático que escamotearia uma ordem jurídica una.

\section{Bibliografia}

AGO Roberto. Communauté internationale et organisation internationale. In: DUPUY, René-Jean. Manuel sur les organisations internationales. Dordrecht: Martinus Nijhoff Publishers, 1998. pp. 3-12.

BAUMAN, Zygmunt. Modernidade líquida. Rio de Janeiro: Jorge Zahar Ed., 2001.

BIELING, Hans-Jürgen. Die Konstitutionalisierung der Weltwirtschaft als Prozess hegemonialer Verstaatlichung, In: BUCKEL, Sonia u.a. (Hrsg.). Hegemonie gepanzert mit Zwang. Baden-Baden: Nomos, 2007. pp. 143-163.

BITTAR, Eduardo Carlos Bianca. O direito na pós-modernidade. Rio de Janeiro: Forense Universitária, 2005.

CAGGIANO, Monica Herman S. Os direitos fundamentais e sua universalização. In: Revista Brasileira do Direito Constitucional, n. 4, jul./dez., 2004.

CANÇADO TRINDADE, Antônio Augusto. Tratado de direito internacional dos direitos humanos - vol. I. Porto Alegre: Sergio Antonio Fabris Editor, 1997.

. A proteção internacional dos direitos humanos e o Brasil (1948-1997): as primeiras cinco décadas. Brasília: UnB, 1998.

CASELlA, Paulo Borba. Fundamentos do direito internacional pós-moderno. Tese de Titularidade apresentada à FADUSP: São Paulo, 2006.

CASAlMIGLIA, Albert. Postpositivismo. Doxa 21:209-220, 1998.

DOLINGER, Jacob. Dignidade: o mais antigo valor da humanidade. os mitos em torno da declaração universal dos direitos do homem e da constituição brasileira de 1988. as ilusões do pós-modernismo/pós-positivismo. a visão judaica. Revista do Direito Constitucional e Internacional. Ano 18 - v. 70 - jan.-mar/2010. pp. 24-90

DUPUY, Pierre-Marie. L'unité de l'ordre juridique international. In: Recueil des Cours. Academie de Droit International de la Haye, tomo 297, 2002.

Some reflections on contemporary international law and the appeal to universal values : a response to Martti Koskenniemi. In: European Journal International Law 16, 2005. pp. 131-137.

EMERSON, Ralph Waldo. Essays and lectures. New York: The Library of América, 1982. 
FASSBENDER, Bardo. The meaning of international constitutional law. In: MacDonald/Johnston (Hrsg.). Towards World Constitutionalism. Amsterdam: R.St.J., 2005.

FISCHER-LESCANO, Andréas; TEUBNER, Gunther. Regime-Kollisionen. Frankfurt am Main: Suhrkamp Verlag, 2006.

GÜNTHER, Klaus. Rechtspluralismus und universaler code der legalität: globalisierung als rechtstheoretisches problem. In: WINGERT, Lutz; GÜNTHER, Klaus. Die öffentlichkeit der vernunft und die vernunft der öffentlichkeit. Frankfurt: Suhrkamp, 2001.

HALTERN, Ulrich. Internationales Verfassungsrecht? Anmerkungen zu einer kopernikanischen Wende. In: Archiv des öffentlichen Rechts 128, 2003. pp. 511-557.

HART, H.L.A. The concept of law. Oxford: Clarendon Press, 1961.

KELSEN, Hans. Teoria pura do direito. São Paulo: Martins Fontes, 1998.

KENNEDY, David. The international human rights movement: part of a problem? In: Harvard Human Rights Journal/Vol. 15.

KOSKENNIEMI, Martti. Global governance and public international law. In: Kritische Justitz, 37, 2004. pp. $241-254$.

. From apology to utopia: the structure of international legal argument. Nova Iorque: Cambridge University Press, 2005.

. The fate of public international law: constitutional utopia or fragmentation? Chorley Lecture: London School of Economics, 2006.

. What is international law for? In: EVANS, Malcolm D. (Edit.). International law. Oxford: Oxford University Press 2006.

LAFER, Celso. A OMC e a regulamentação do comércio internacional: uma visão brasileira. Porto Alegre: Livraria do Advogado, 1998.

LEWANDOWSKY, Enrique Ricardo. Globalização e soberania. In: CASELLA, Paulo Borba; CELLI, Umberto. Direito internacional, humanismo e globalidade. São Paulo: Atlas, 2008.

MELLO, Celso D. de Albuquerque. Direito internacional americano: estudo sobre a contribuição de um direito regional para a integração econômica. Rio de Janeiro: Renovar, 1995.

PEREIRA, Ana Cristina Paulo. Diferentes aspectos dos sistemas de integração da União Européia e do MERCOSUL: uma abordagem sintética e comparativa. In: PEREIRA, Ana Cristina Paulo. MERCOSUL e união européia: perspectivas da integração regional. Rio de Janeiro: Lúmen Júris, 2006. pp. 193-216.

PIOVESAN, Flávia. Direitos humanos e o direito constitucional internacional. São Paulo: Editora Max Limonad Ltda., 1996. 
. Direitos humanos globais, justiça internacional e o brasil. In: AMARAL JUNIOR, Alberto do, org; Perrone-Moisés, Cláudia, org. O Cinquentenário da Declaração Universal dos Direitos do Homem. São Paulo: EDUSP, 1999.

. Direitos humanos: desafios da ordem internacional contemporânea. In: PIOVESAN, Flávia, coord. Direitos Humanos. Curitiba: Juruá, 2007.

SANTOS, Boaventura de Souza. Uma concepção multicultural de direitos humanos. In: Lua Nova: Revista de Cultura e Política 39, 1997, pp. 105-124.

SINGER, Peter. One world. New Haven e Londres: Yale University Press, 2004.

SOARES, Mário Lúcio Quintão. MERCOSUL - Direitos humanos, globalização e soberania. Belo Horizonte: Del Rey, 1999.

WALZER, Michael. Thick And Thin, Moral Argument at Home and Abroad. Notre Dame: undp, 1994. 